\title{
Roost composition and sexual segregation in a lowland population of Daubenton's bats (Myotis daubentonii).
}

\author{
Type: \\ Original paper
}

\begin{abstract}
:
Using data from 1100 day roosts containing a minimum of 9424 Myotis daubentonii bats, we compare the distribution of adult males, adult females, and juveniles, within SchweglerTM box roosts distributed across 394ha of woodland adjacent to a river corridor in lowland England.
\end{abstract}

Five social groups, containing both males and females (each comprising 55 - 230 adult bats per annum, using 37 - 127 known roosts per colony), occupy discrete roosting areas to which individuals show high inter-annual fidelity.

Natal philopatry is also high, compared to between colony movements, for both sexes in our study population.

Despite considerable spatial overlap and variability in roost composition over the summer (April to October), related to temporal changes in reproductive status, there is sexual segregation within day roosts. Bachelor (adult male dominated) roosts are situated significantly further from water than maternity (adult female or juvenile dominated) roosts on average. This spatial partitioning between maternity and bachelor roosts operates within rather than between colony home roost ranges, however, with adult males from some social groups found roosting closer to water than are adult females from adjacent colonies.

The co-occurrence of maternity and bachelor groups roosting in close proximity, including extensive spatial overlap in roosts occupied, and temporal overlap during roost sharing between the sexes, provides novel insights into social organisation and potential drivers of sexual segregation and mating strategies for this widespread and common species within lowland habitats.

\section{Keywords:}

landscape, philopatry, occupancy, colony, fidelity, maternity, male, social 


\title{
Roost composition and sexual segregation in a lowland population of Daubenton's bats (Myotis daubentonii).
}

\author{
Danielle M. Linton ${ }^{1 *}$ and David W. Macdonald ${ }^{1}$ \\ ${ }^{1}$ University of Oxford, Department of Zoology, Wildlife Conservation Research Unit \\ (WildCRU), The Recanati-Kaplan Centre, Tubney House, Abingdon Road, Tubney, OX13 \\ 5QL, UK
}

*Corresponding author: daniellemlinton@gmail.com

\begin{abstract}
Using data from 1100 day roosts containing a minimum of 9424 Myotis daubentonii bats, we compare the distribution of adult males, adult females, and juveniles, within Schwegler ${ }^{\mathrm{TM}}$ box roosts distributed across 394ha of woodland adjacent to a river corridor in lowland England.

Five social groups, containing both males and females (each comprising 55 - 230 adult bats per annum, using 37 - 127 known roosts per colony), occupy discrete roosting areas to which individuals show high inter-annual fidelity. Natal philopatry is also high, compared to between colony movements, for both sexes in our study population. Despite considerable spatial overlap and variability in roost composition over the summer (April to October), related to temporal changes in reproductive status, there is sexual segregation within day roosts. Bachelor (adult male dominated) roosts are situated significantly further from water than maternity (adult female or juvenile dominated) roosts on average. This spatial partitioning between maternity and bachelor roosts operates within rather than between colony home roost ranges, however, with adult males from some social groups found roosting closer to water than are adult females from adjacent colonies.

The co-occurrence of maternity and bachelor groups roosting in close proximity, including extensive spatial overlap in roosts occupied, and temporal overlap during roost sharing between the sexes, provides novel insights into social organisation and potential drivers of sexual segregation and mating strategies for this widespread and common species within lowland habitats.
\end{abstract}

Keywords: occupancy, colony, fidelity, philopatry, maternity, male, landscape, social 


\section{INTRODUCTION}

Daubenton's bat, M. daubentonii (Kuhl, 1817) (Chiroptera: Vespertilionidae) is common and widespread across the Palearctic where it specialises in hunting low over calm water surfaces by aerial hawking or trawling (Todd \& Waters 2017), feeding predominantly on Chironomids (Diptera, Nematocera) (Swift \& Racey 1983, Vesterinen et al. 2016). Male sociality, where bachelor groups containing multiple males have been reported sharing day roosts during the active season, is known to occur in this species (Encarnação et al. 2005, Nardone et al. 2015), possibly due to their foraging strategy, which is dependent on the location of patchily distributed prey, and may therefore involve some level of group cooperation or information sharing (Safi \& Kerth 2007).

Previous studies have demonstrated that sexual segregation occurs during the maternity period in $M$. daubentonii, with females and their dependent offspring occupying roosts closer to optimal foraging habitat compared to bachelor roosts, and males typically travelling further during foraging bouts than females, especially lactating females which return to their offspring in the maternity roost several times per night (Encarnação et al. 2005, Senior et al. 2005).

Landscape topography and local microclimate can influence the distribution and quality of foraging sites, i.e. size of waterbodies, water surface characteristics, and prey availability, along an elevational gradient (Warren et al. 2000). Male $M$. daubentonii are typically more widely distributed, occurring at higher altitude within sub-optimal habitat, compared to females which, due to their higher energy demands during pregnancy and lactation, are restricted to lower elevation roosts and foraging sites where climatic conditions are more favourable and prey availability is higher (Russo 2002, Dietz et al. 2006, Angell et al. 2013). It has been suggested that competitive exclusion exists where females, and some dominant males, aggressively defend prime foraging areas and occupy the best roosts, forcing the majority of males into marginal habitat (Encarnação et al. 2005, Nardone et al. 2015), which is known to influence patterns of paternity (Senior et al. 2005, Angell et al. 2013).

This investigation is the first to present long-term data on roost composition and occupancy by male and female $M$. daubentonii from multiple social groups, each containing adult bats of both sexes, found in adjacent but spatially exclusive roost areas across an area of contiguous 
woodland habitat where roost availability is not a limiting factor (August et al. 2014) and optimal foraging habitat is also abundant within the surrounding lowland landscape.

Based on existing knowledge of sexual segregation patterns in M. daubentonii we expected that:

i) There would be sexual segregation in day roosts, with adult females and juveniles occupying maternity roosts, and adult males occupying bachelor roosts.

ii) Maternity roosts would be situated closer to optimal foraging habitat (open water) than bachelor roosts.

\section{MATERIALS AND METHODS}

Wytham Woods ( $51^{\circ} 77^{\prime} \mathrm{N}, 1^{\circ} 33^{\prime} \mathrm{W}$ ) is a predominantly deciduous forest situated on a hill (elevation 60 - 165m a.s.l.) surrounded by the floodplain of the River Thames. Within a 4km radius of the site there is an extensive network of rivers (including over $17 \mathrm{~km}$ of river channel exceeding $5 \mathrm{~m}$ in width), streams and a canal, which provide both foraging habitat and commuting routes to additional expanses of open water at numerous ponds, lakes and a large reservoir (149.1ha surface area). A further complex of more than 30 former aggregates extraction site (gravel pit) lakes is situated 4 - $10 \mathrm{~km}$ to the south-west. Wytham is the largest block of woodland within this $144 \mathrm{~km}^{2}$ area (see Fig 1).

There are 1265 Schwegler $^{\mathrm{TM}}$ woodcrete $2 \mathrm{M}$ and $1 \mathrm{~B}$ nest boxes distributed across the 394ha of woodland on the Wytham estate, maintained by the Edward Grey Institute for Field Ornithology (EGI) for long-term monitoring of great tit, Parus major, and blue tit, Cyanistes caeruleus breeding populations (Perrins 1965, Hinks et al. 2015). Bats were first recorded roosting in the boxes by EGI researchers in 1982 (A. Gosler, unpublished data).

Over 52,000 box checks (mean $42.0 \pm 15.9$ SD checks per box) searching for bats and bat droppings have been undertaken between April - October over 21 years (1998 - 2018). To date, 412 boxes have been recorded as occupied by M. daubentonii on a minimum of 1456 occasions, based on the presence of characteristic (medium-sized, dark and wet) droppings or bats (which is likely to represent only a small proportion of actual occupancy rates). Roosting M. daubentonii have been found in 382 boxes on 1100 occasions (1 - 12 day roosts recorded per box) and these roosts contained at least 9424 bats (1 - 156 bat occupations recorded per 
box). Ringed individuals comprise 7033 (74.6\%) of these records. Our dataset is known to include over 2534 individuals, represented between 1 to 32 times (mean $2.85 \pm 3.53$ SD encounters per ringed bat) over 1 to 13 years (mean $2.47 \pm 2.54$ years per ringed bat).

For 915 (83.2\%) roost occupations the age (adult or juvenile) and sex of all bats present ( $\mathrm{n}=$ 7202 bats, 1 - 37 bats per day roost) was recorded. For the remaining 185 roosts (16.8\%); females were not disturbed whilst heavily pregnant or with non-volant dependent young in maternity groups ( $\mathrm{n}=96$ roosts, containing a minimum of 1191 bats, see Fig $2 \mathrm{~B}$ ). The full composition (known age and sex status of all bats present) of another 89 roosts, containing a minimum of 1031 bats, could not be determined when bats were not disturbed e.g. during radio-tracking ( $n=39$ roosts), due to escapees ( $n=33$ bats, 1 or 2 individuals from 27 roosts), or because age status was not recorded for unringed individuals ( $\mathrm{n}=168$ bats in 23 roosts). Overall, the status (age and sex) of 8570 (90.1\%) bats was recorded from 1067 roosts.

Juveniles were typically identified by the presence of unossified epiphyseal cartilage at the finger joints (Hoying \& Kunz 1998). Late in the season, however, once the metacarpalphalangeal gaps had fused, a suite of secondary characteristics, including fresh 'tacky' wing membranes, grey pelage, and light weight were used in age assessment of unringed bats (Linton \& Macdonald 2018).

The reproductive condition of bats was determined by visual inspection or weight to assess pregnancy, and examination of nipple condition to assess recent breeding status, in females (Racey 1974), and assessment of testes size, and distension and pigmentation of the epididymides in males (Entwistle et al. 1998).

All procedures performed in this study involving animals were in accordance with the official standards of the institution at which this research was conducted (University of Oxford). Furthermore, all work was carried out under project licences from the statutory nature conservation organisation (English Nature / Natural England).

Roosts were classified as containing bachelor groups (adult male dominated, $n=387$ roosts), or maternity groups (adult female and/or juvenile dominated, $n=659$ roosts). Only 34 (3.1\%) roosts were excluded from this classification due to incomplete information on roost composition. Only 20 (1.8\%) roosts contained an equal number of adult males alongside females or juvenile bats (all small groups found in autumn containing two to six individuals). 
Individual bats were assigned to particular social groups on the basis of their complete ring capture histories, updating the social network analyses of August et al. (2014) and Culina et al. (2017). Bats found in day roosts exclusively with other bats from a single social group (A - E, see Fig 3B) were also classified as belonging to that colony (716 females and 917 males). Bats found roost sharing with other bats from more than one social group were assigned to whichever social group was most frequently dominant across all known day roosts for that individual (228 females and 550 males, see Fig 3C - F). Misclassification of a small proportion of bats due to this probability based approach is not considered likely to affect the results presented in this study. Only 64 individuals (16 females and 48 males) were captured only once or twice in unringed groups, mixed roosts, or found roost sharing with different social groups between captures (see Fig 3C - F).

Spatial analyses and mapping were conducted using QGIS (QGIS Development Team 2018). Statistical analyses were undertaken in R (R Core Team 2018), with Pearson's Chi-square test for independence used to evaluate sexual segregation, and Kolmogorov-Smirnov tests used to compare non-parametric distributions of bat and box data relative to distance from water. Bonferroni correction was applied to all P-values to account for multiple pairwise comparisons. Density plots of spatial distributions were produced using the R package ‘ggridges’ (Wilke 2018).

\section{RESULTS}

There was evidence of sexual segregation within day roosts (Pearson's Chi-squared test, $\chi^{2}=$ 2668.7, $d f=2, \mathrm{P}<0.001$ ), with 1177/2704 (43.5\%) adult males found in 265 day roosts with no adult females present, and 1342/2227 (60.3\%) adult females found in 264 day roosts with no adult males present. The remaining 1527/2704 (56.5\%) adult males and 885/2227 (39.7\%) adult females were found in 256 day roosts containing adult bats of both sexes.

\section{Temporal Patterns in Roost Composition}

Our dataset comprises 365 bachelor roosts, containing 2697 bats (1 - 33 bats per group) for which the full roost composition was recorded (see Fig 2A) of which 2392 (88.7\%) were 
adult males, 223 (8.3\%) were adult females, 62 (2.3\%) were juvenile males and 20 (0.7\%) were juvenile females. During May to July only 18/213 (8.5\%) bachelor roosts comprised solitary adult males, and only six of these individuals were in the early stages of spermatogenesis, the rest were not yet in breeding condition. In contrast, during August to October 73/150 (48.7\%) bachelor roosts comprised solitary adult males, and over 75\% of these were in or entering reproductive condition, based on testes size and epididymal filling. From May to September adult females were present within 126 (46.9\%) of the 271 bachelor groups found (excluding solitary male roosts) (see Fig 2A), the majority of these females were non-breeding, but rarely heavily pregnant or lactating females, with or without their offspring, were found in bachelor groups. The mean adult sex ratio ( $\sigma^{x}:$ ㅇ $)$ within bachelor roosts (excluding solitary males) was 1:0.11 ( \pm 0.14 SD). Juvenile males were found within 35 (12.9\%) and juvenile females within 14 (5.2\%) bachelor groups from mid-July onwards.

Because maternity groups containing heavily pregnant females or non-volant dependent juveniles were not usually disturbed our dataset for which the full roost composition is known comprises only 42 maternity roosts from May and June, compared to 487 roosts from July to October (see Fig 2B). 4439 bats were present within these 529 roosts (group size varied from 1 - 37 bats), 1849 (41.7\%) were adult females, 252 (5.7\%) were adult males, 1322 (29.8\%) were juvenile males, and 1016 (22.9\%) were juvenile females. Parturition typically occurred from the end of May into early June, with small roosts of 1 - 3 females sometimes found that had recently given birth (DML, personal observation). During July and August, the ratio of adult females to juveniles in maternity roosts was close to unity (1409:1410 or 1:1), but during September and October the proportion of adult females present decreased markedly (141:832 or 1:5.9) (see Fig 2B). During May to July 139/147 (94.6\%) maternity groups contained adult females. Through August 157/181 (86.7\%) maternity groups still contained adult females. By September juvenile only groups predominated with only 59/155 (38.1\%) roosts containing adult females. Only small groups of juveniles, particularly juvenile males, remained in October (see Fig 2B).

The mean adult sex ratio ( $\sigma^{x}:$ ㅇ ) within maternity roosts (excluding solitary females) was 0.23:1 ( \pm 0.48 SD). Adult males were present within 133/459 (29.0\%) maternity roosts (excluding solitary female or juvenile roosts) and were slightly more likely to be found alongside adult females than with juvenile only groups, although this may simply be due to the temporal occurrence of adults relative to juveniles (see Fig 2). Mean group size in both bachelor and maternity roosts was larger during June and July (9.99 \pm 7.14 SD for bachelor 
groups, and 12.10 \pm 8.20 SD for maternity groups) than during August and September (4.07 \pm 4.34 SD for bachelor groups, and $7.72 \pm 6.33$ SD for maternity groups).

Regardless of age or roost classification, males in breeding condition (based on distension of their epididymides) were encountered sharing day roosts with potentially receptive females on 136 occasions from late July onwards within this summer habitat.

\section{$\underline{\text { Spatial Patterns of Sexual Segregation }}$}

Bachelor groups were located in 202 boxes (1 - 9 recorded occupations per box), and maternity groups in 313 boxes ( 1 - 11 roost encounters per box). 138 boxes are known to have been occupied by both bachelor groups and maternity roosts (see Fig 3A). Given the likely magnitude of unrecorded roost occupancy (each box was checked on $<10 \%$ days when bats were likely to be present in their summer roosts, during May to September), the true extent of spatial roost overlap is probably much greater.

Bats were not randomly distributed within available boxes, but all age and sex classes (adult males, adult females, juvenile males and juvenile females) were concentrated within roosts closer to water (Kolmogorov-Smirnov tests, $\mathrm{P}<0.0001$ for all two-sample comparisons per sex and age class against the distribution of available boxes) and this was not an artefact of biased survey effort (Kolmogorov-Smirnov tests, $\mathrm{P}<0.0001$ for all comparisons of bat data against the distribution of box checks). Overall, 62.6\% $(n=5898)$ of bats were found within $18.7 \%(n=237)$ of boxes, specifically those situated within $700 \mathrm{~m}$ of water. Whereas only $2.2 \%$ of bats $(n=204)$ were encountered within the $16.8 \%(n=213)$ of boxes located over $1,500 \mathrm{~m}$ from water.

Despite the considerable overlap in roost occupancy and close proximity of bachelor groups and maternity roosts observed (see Fig 3A), adult females were distributed significantly closer to water than adult males, both overall, and per social group (see Fig 4) (KolmogorovSmirnov tests, $\mathrm{P}<0.0001$ in all two-sample comparisons between the sexes).

\section{$\underline{\text { Social Group Fidelity and Natal Philopatry }}$}

The majority of capture events for both female $(2723 / 3132=86.9 \%)$ and male $(2745 / 3804=$ $72.2 \%$ ) ringed bats occurred within their colony home roost range in day roosts shared almost 
exclusively with other bats from the same social group (see Fig 3C - F). Mixed day roosts containing bats from social groups A and B, or A and C, along the boundaries of their respective colony home roost ranges (see Fig $3 \mathrm{~B}$ ) accounted for most other captures, with females $(397 / 3132=12.7 \%)$ less likely to be found in mixed day roosts than males $(1042 / 3804=27.4 \%)$ (Pearson's Chi-squared test, $\chi^{2}=216.85, d f=1, \mathrm{P}<0.001$, including bats from social groups A, B and C only). Mixed day roosts were more likely to be bachelor groups than maternity groups (Pearson's Chi-squared test, $x^{2}=31.97, d f=1, \mathrm{P}<0.001$, including roosts from social groups A, B and C only). Only 12 (0.38\%) female and 17 male $(0.44 \%)$ ring recaptures were classed as between-colony ring movements (see Fig 3C - F) of which 8 female and 5 male ring movements were known to be transient as these bats were subsequently found again roosting back with their original social groups.

Between 2006 - 2016 a total of 1191 bats were ringed as juveniles, of which 193/464 (41.6\%) females and 199/727 (27.5\%) males were subsequently recaptured as adults. Of these, 192 females and 193 males showed natal philopatry i.e. were found in the same social group as juveniles and adults. Only 1 female and 6 males were found in different social groups as juveniles than as adults.

\section{DISCUSSION}

Long-term monitoring of numerous roosts occupied by several neighbouring bat colonies, with high roost occupancy rates and the ability to fully ascertain the composition (known age and sex status) of roosting groups across our study system provides an unprecedented dataset with which to elucidate patterns of sexual segregation and social organisation of roost use in a lowland M. daubentonii population. 7095/9424 (75.3\%) of $M$. daubentonii encounters were concentrated within the 535/1265 (42.3\%) boxes situated within $1 \mathrm{~km}$ of water, and this proportion was similar across age and sex classes (73.4 - 76.1\%). Despite this similarity in distribution patterns, and despite a high degree of spatial overlap in roost occupancy (with many boxes used by both bachelor and maternity groups), the spatial distribution of adult females was concentrated significantly closer to water than the spatial distribution of adult males. Comparison between social groups, however, reveals that patterns of sexual segregation are not optimised such that all females are concentrated in roosts closer to water, but roost selection is restricted to areas within each colony home roost range (see Fig 3B). Creating a situation where the known spatial distribution of adult males from some colonies 
is almost entirely closer to water than the known spatial distribution of adult females from other colonies (compare A (males) with E (females), and C (males) with D (females) see Fig 4B).

At a national (Langton et al. 2009) and regional scale (Dietz et al. 2006) the abundance or density of $M$. daubentonii is known to be highly variable, and is likely influenced by resource availability within the surrounding landscape, especially optimal foraging habitat for this species, which specialises in foraging over open water (Jones \& Rayner 1988, Rydell et al. 1996). We observe sexual segregation within our study system despite high roost availability and abundant optimal foraging habitat within the surrounding landscape. Roost availability is not considered to be a limiting factor within our study system as each social group (known to contain 55 - 230 adult bats per annum) has occupied 37 - 127 known roosts per colony home roost range (see Fig 3B), but occupancy rates (especially for the less frequently encountered social groups C, D and E, see Figures 3 and 4, and Culina et al. 2017) indicate that these bats must also have access to additional roosts, e.g. tree roosts and possibly bridges and buildings in the surrounding landscape (Ngamprasertwong et al. 2014). Sexual segregation within our study system does not appear to be a result of competitive exclusion and occupancy of prime roost sites or habitat by breeding females (August et al. 2014, this study). Bachelor roosts are often found in close proximity (within $250 \mathrm{~m}$ ) to maternity groups, and many roosts have been occupied by both bachelor and maternity groups, even within the same season.

Our study demonstrates, for the first time, that adult male and female $M$. daubentonii coexist within social groups, with high roost fidelity and natal philopatry exhibited in both sexes, in a lowland habitat where an elevational gradient (i.e. availability of adjacent upland areas) does not exist. The lower proportion of juvenile males (compared to juvenile females) recaptured as adults within their natal colonies might be due to lower survival or higher dispersal rates, or both. More males $(n=7)$ than females $(n=1)$ have been found roosting with more than one social group as juveniles (including transient between-colony ring movements where the same individual was subsequently found roosting back with their previous social group). More male than female juveniles were encountered each year within our study system (with the exception of 2016 when the sex ratio was close to unity) with an overall juvenile sex ratio of ( $\sigma^{x}:$ ㅇ ) of $1.25: 1$ (or $55.7 \%$ male and $44.3 \%$ females) which could be due, at least in part, to higher dispersal rates of juvenile males into our study system from the surrounding landscape. In the absence of genetic pedigree data for this population our estimates of natal philopatry, and social group membership, are based on behavioural information rather than 
genetic analyses which could reveal higher rates of between-colony dispersal than capture records are able to detect.

Previous studies describing sexual segregation in $M$. daubentonii populations at a landscape scale have been undertaken in study areas at high elevation, e.g. over $800 \mathrm{~m}$ a.s.l. in Italy (Russo 2002), or across an elevational gradient e.g. from 144 - 498m a.s.l. in Germany (Dietz et al. 2006), and from 70 - 260m a.s.l. in Wharfedale, UK (Senior et al. 2005, Angell et al. 2013), these studies each reported higher proportions of females compared to males at lower elevations. The overall adult sex ratio $\left(\sigma^{\star}: \circ\right)$ observed in our lowland study system (at $60-$ $165 \mathrm{~m}$ a.s.l.) is approximately 3:2 (based on 2799 encounters with 891 adult males, mean 3.14 \pm 3.49 SD encounters over mean $3.29 \pm 2.98$ years per adult male, and 2343 encounters with 610 adult females, mean $3.84 \pm 4.68$ SD encounters over mean $3.09 \pm 2.63$ SD years per adult female). Whether sexual segregation occurs within foraging habitats, whether males travel further than females when foraging or any differences in habitat selection occur, as has been observed in previous studies (Russo 2002, Dietz et al. 2006), is worthy of further investigation within our lowland study area.

The degree of roost sharing observed between males in breeding condition and potentially receptive females during July to October indicates that some mating is highly likely to occur between bats from the same or neighbouring social group within their summer habitat in our study system. The extent to which local males are responsible for paternity relative to outbreeding at (as yet unidentified) swarming or hibernation sites in this population is worthy of further investigation, especially given the apparent rates of natal philopatry we observe for both sexes, and the known flexibility of mating systems in $M$. daubentonii related to spatial patterns of sexual segregation (Angell et al. 2013).

Improving our understanding of social organisation and spatio-temporal patterns of roost sharing in M. daubentonii is also relevant to assessment of human health risk and models of disease transmission for e.g. European Bat Lyssavirus 2 (EBLV2) (Atterby et al. 2010, August et al. 2014). This study also demonstrates that entire social groups can be highly dependent on relatively small colony home roost ranges which is important for conservation management planning e.g. when assessing the potential impact of large-scale habitat modification such as clear-felling forestry operations, or predicting the long-term effects of ash dieback for woodland bat populations. 


\section{ACKNOWLEDGEMENTS}

This work was generously supported by a grant to DWM from S. Durie, with additional support from the Peoples' Trust for Endangered Species. The authors thank Fiona Mathews (Chair of the UK Mammal Society) and all the volunteers who have contributed to data collection for the Wytham Bat Project. We also thank the EGI researchers and field staff, including Ben Sheldon and Ella Cole, as well as Nigel Fisher, Conservator of Wytham Woods, for their continued help and cooperation. The authors would also like to thank the two anonymous reviewers whose comments greatly contributed to improving this manuscript. We dedicate this paper to Rob Strachan who collected the early data (1998 - 2005) and introduced DML to bats roosting in the EGI nest boxes at Wytham.

\section{LITERATURE CITED}

Angell, R.L., Butlin, R.K. \& Altringham, J.D. (2013) Sexual Segregation and Flexible Mating Patterns in Temperate Bats. PLoS ONE, 8(1), e54194.

doi:10.1371/journal.pone.0054194

Atterby, H., Aegerter, J.N., Smith, G.C., Conyers, C.M., Allnutt, T.R., Ruedi, M. \& MacNicoll, A.D. (2010) Population genetic structure of the Daubenton's bat (Myotis daubentonii) in western Europe and the associated occurrence of rabies. European Journal of Wildlife Research, 56, 67 - 81.

August, T.A., Nunn, M.A., Fensome, A.G., Linton, D.M. \& Mathews, F. (2014) Sympatric woodland Myotis bats form tight-knit social groups with exclusive roost home ranges. PLoS One, 9(10), e112225

Culina, A, Linton, D.M. \& Macdonald, D.W. (2017) Age, sex and climate factors show different effects on survival of three different bat species in a woodland bat community. Global Ecology and Conservation, 12, 263 - 271.

Dietz, M., Encarnação, J.A. \& Kalko, E.K.V. (2006) Small scale distribution patterns of female and male Daubenton's bats (Myotis daubentonii). Acta Chiropterologica, 8(2), 403 415. 
Encarnação, J.A., Keirdorf, U, Holweg, D., Jasnoch, U. \& Wolters, V. (2005) Sex-related differences in roost-site selection by Daubenton's bats Myotis daubentonii during the nursery period. Mammal Review, 35, 285 - 294.

Entwistle, A.C., Racey, P.A. \& Speakman, J.R. (1998) The reproductive cycle and determination of sexual maturity in male brown long-eared bats, Plecotus auritus (Chiroptera: Vespertilionidae). Journal of Zoology, London, 244, 63 - 70.

Hinks, A.E., Cole, E.F., Daniels, K.J., Wilkin, T.A., Nakagawa, S. \& Sheldon, B. (2015) Scale-dependent Phenological Synchrony between Songbirds and Their Caterpillar Food Source. The American Naturalist, 186(1), 84 - 97.

Hoying, K.M. \& Kunz, T.H. (1998) Variation in size at birth and post-natal growth in the insectivorous bat Pipistrellus subflavus (Chiroptera: Vespertilionidae). Journal of Zoology, 245, 15 - 27.

Jones, G. \& Rayner, J.M.V. (1998) Flight performance, foraging tactics and echolocations in free-living Daubenton's bats, Myotis daubentonii (Chiroptera: Vespertilionidae). Journal of Zoology, London, 215, 113 - 132.

Langton, S.D., Briggs, P. \& Haysom, K.A. (2009) Daubenton’s bat distribution along rivers developing and testing a predictive model. Aquatic Conservation: Marine and Freshwater Ecosystems, doi:10.1002/aqc.1077

Linton, D.M. \& Macdonald, D.W. (2018) Spring weather conditions influence breeding phenology and reproductive success in sympatric bat populations. Journal of Animal Ecology, 87(4), 1080 - 1090.

Nardone, V., Cistrone, L., Di Salvo, I., Ariano, A., Migliozzi, A., Allegrini, C., Ancillotto, L., Fulco, A. \& Russo, D. (2015) How to Be a Male at Different Elevations: Ecology of IntraSexual Segregation in the Trawling Bat Myotis daubentonii. PLoS ONE, 10(7), e0134573. doi:10.1371/journal.pone.0134573

Ngamprasertwong, T., Piertney, S.B., Mackie, I. \& Racey, P.A. (2014) Roosting habits of Daubenton's bat (Myotis daubentonii) during reproduction differs between adjacent river valleys. Acta Chiropterologica, 16(2), 337 - 347.

Perrins, C.M. (1965) Population fluctuations and clutch size in the great tit Parus major L. Journal of Animal Ecology, 34, 601 - 647. 
QGIS Development Team (2018) QGIS Geographic Information System. Open Source Geospatial Foundation Project. URL http://qgis.osgeo.org

R Core Team (2018) R: A language and environment for statistical computing. R Foundation for Statistical Computing, Vienna, Austria. URL https://www.R-project.org/

Racey, P.A. (1974) Ageing and assessment of reproductive status of Pipistrelle bats, Pipistrellus pipistrellus. Journal of Zoology London, 173(2), 264 - 271.

Russo, D. (2002) Elevation affects the distribution of the two sexes in Daubenton's bats Myotis daubentonii (Chiroptera: Vespertilionidae) from Italy. Mammalia, 66(4), 543 - 551.

Rydell, J., Entwistle, A. \& Racey, P.A. (1996) Timing of foraging flights of three species of bats in relation to insect activity and predation risk. Oikos, 76, 243 - 252.

Safi, K. \& Kerth, G. (2007) Comparative analyses suggest that information transfer promoted sociality in male bats in the temperate zone. The American Naturalist, 170(3), 465 - 472.

Senior, P., Butlin, R.K. \& Altringham, J.D. (2005) Sex and segregation in temperate bats. Proceedings of the Royal Society B, 272, 2467 - 2473.

Swift, S.M. \& Racey, P.A. (1983) Resource partitioning in two species of vespertilionid bats (Chiroptera) occupying the same roost. Journal of Zoology London, 200, 249 - 259.

Todd, V.L.G. \& Waters, D.A. (2017) Small scale habitat preferences of Myotis daubentonii, Pipistrellus pipistrellus, and potential aerial prey in an upland river valley. Acta Chiropterologica, 19(2), 255 - 272.

Vesterinen, E.J., Ruokolainene, L., Wahlberg, N., Pena, C., Roslin, T., Laine, V.N., Vasko, V. Saaksjarvi, I., Norrdahl, K. \& Lilley, T.M. (2016) What you need is what you eat? Prey selection by the bat Myotis daubentonii. Molecular Ecology, doi:10.1111/mec.13564.

Warren, R.D., Waters, D.A., Altringham, J.D. \& Bullock, D.J. (2000) The distribution of Daubenton's bats (Myotis daubentonii) and pipistrelles (Pipistrellus pipistrellus) (Vespertilionidae) in relation to small-scale variation in riverine habitat. Biological Conservation, 92, 85 - 91.

Wilke, C.O. (2018) ggridges: Ridgeline Plots in 'ggplot2'. R package version 0.5.1. https://CRAN.R-project.org/package=ggridges 
Figure 1

Download source file $(745.2 \mathrm{kB})$

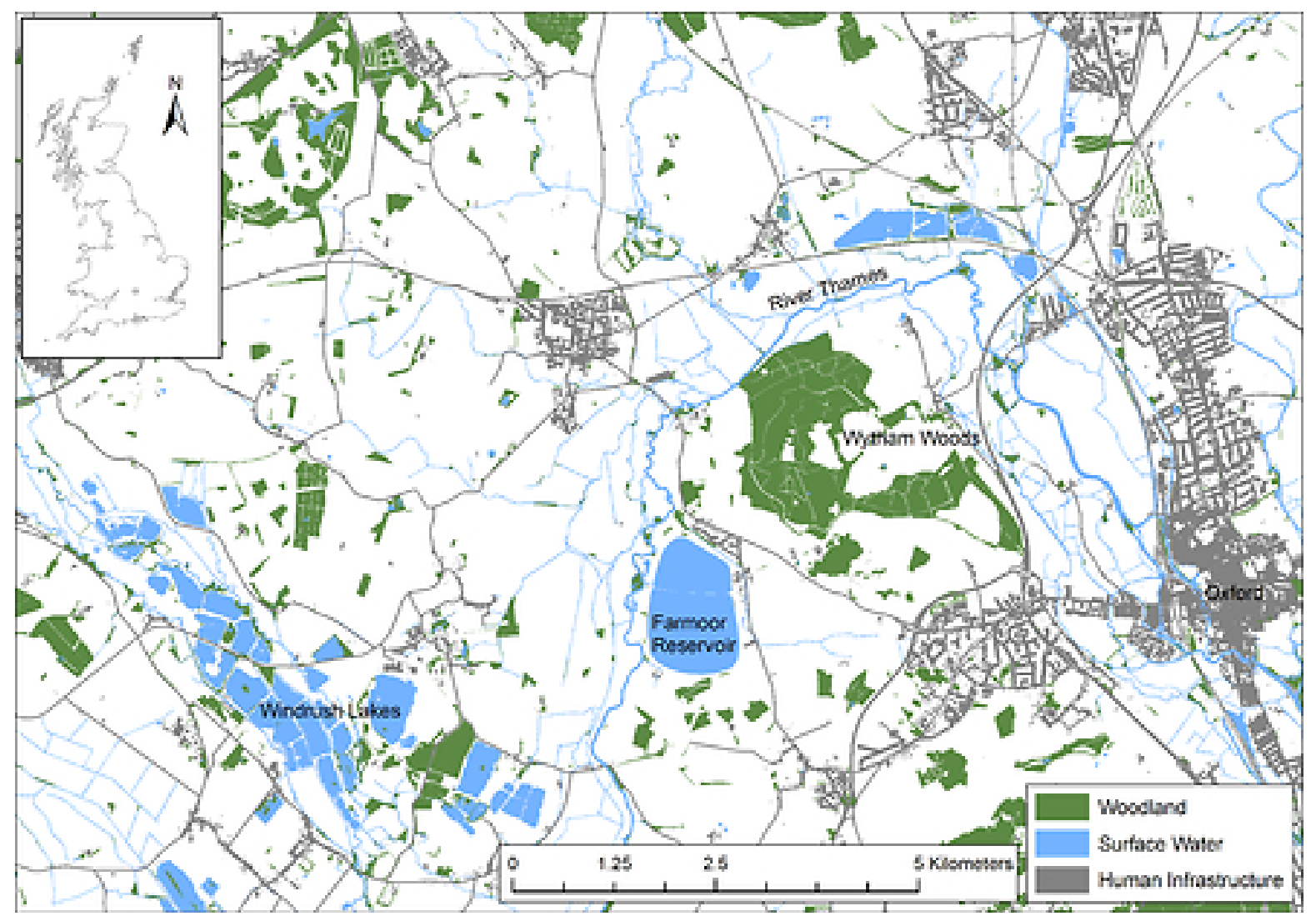

Figure 1. Location map of study area, including potential Myotis daubentonii foraging habitat (open water) in the surrounding landscape (lowland floodplain of the River Thames, Oxfordshire, UK). 


\section{Figure 2}

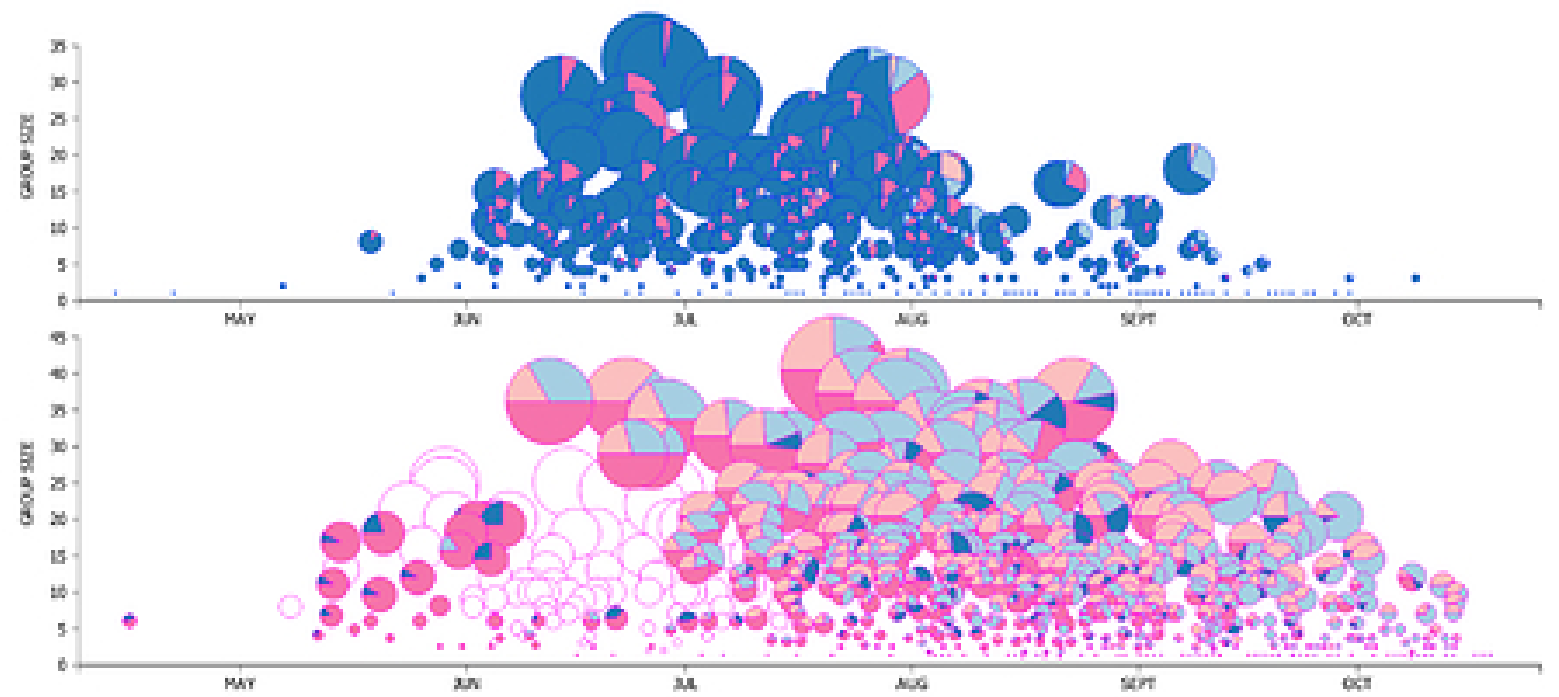

Figure 2. Seasonal patterns in Myotis daubentonii roost composition and group size, for A) bachelor (adult male dominated) groups, and B) maternity (adult female and/or juvenile dominated) roosts. Pie charts each represent a day roost and depict the proportion of adult males (dark blue), adult females (dark pink), juvenile males (light blue) and juvenile females (light pink) present. Maternity groups that were not disturbed, so their exact composition is unknown, for which the group size was estimated are also shown (empty pink circles). 


\section{Figure 3}

Download source file (2.01 MB)

a)

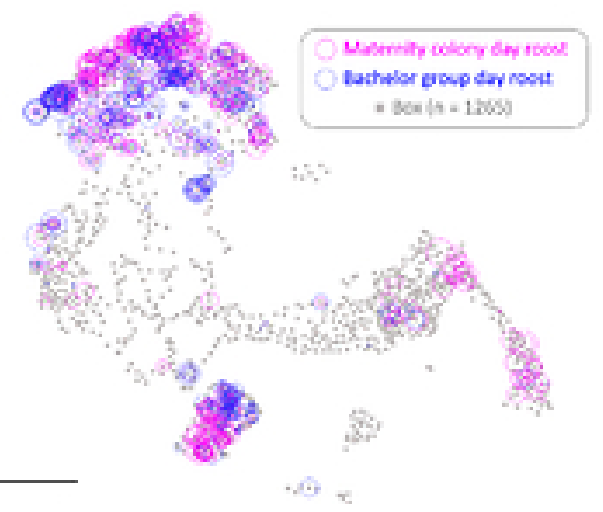

c)

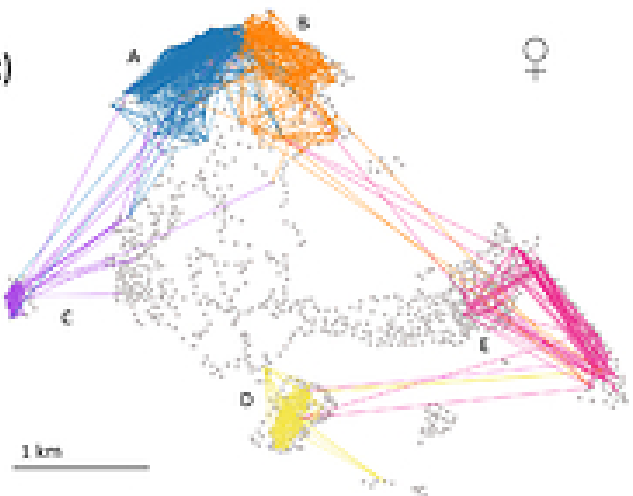

e)

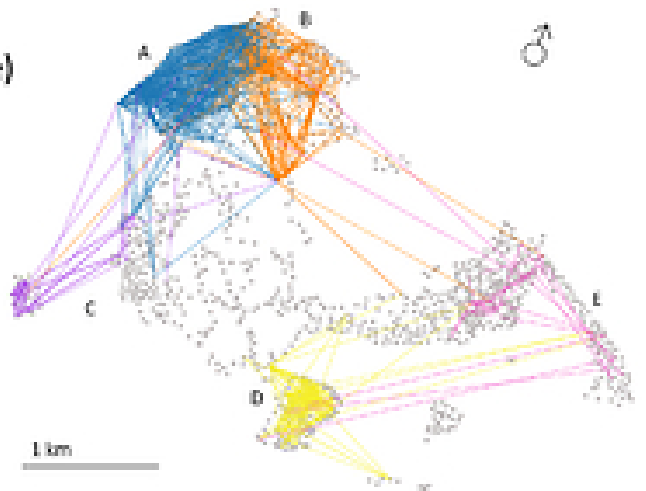

b)
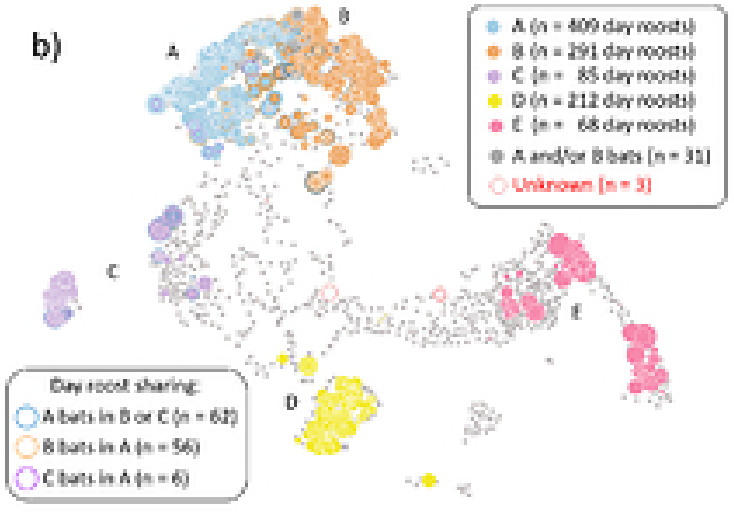

d)

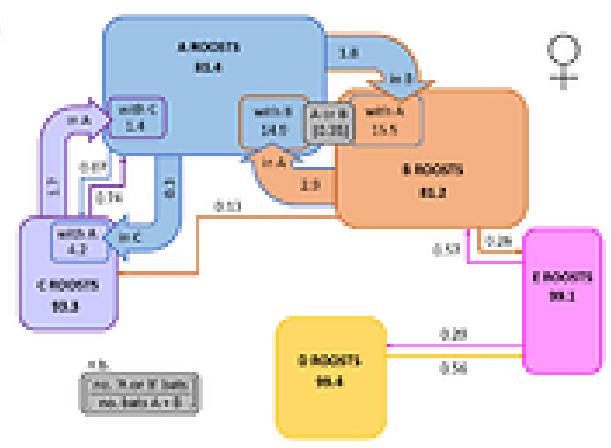

f)

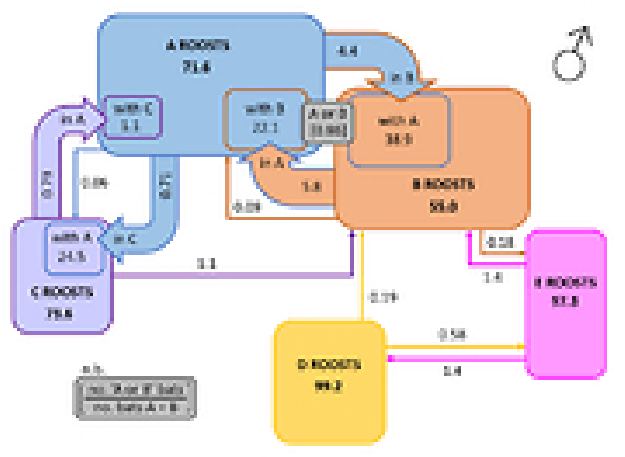

Figure 3. Spatial distribution of Myotis daubentonii day roosts and ring movements per social group across Wytham Woods.

A) bachelor (adult male dominated) groups (blue) and maternity (adult female and/or juvenile dominated) colony day roosts (pink) are shown with circle size indicating group size ( $\mathrm{n}=1-45$ bats per day roost, and $1-12$ known occupations per box, $n=1100$ day roosts distributed across 382 boxes).

B) Myotis daubentonii day roosts colour coded by dominant social group (A - E), with roost sharing indicated by coloured outlines representing the colony of bats in the minority (A, B or C).

C) Between roost movements of ringed female bats, colour coded per social group.

D) The percentage of female ring capture records per social group that occur exclusively with other members of that colony (A - E), or in mixed day roosts ('with $\mathrm{A} / \mathrm{B} / \mathrm{C}$ ' for the dominant social group and 'in $\mathrm{A} / \mathrm{B} / \mathrm{C}$ ' for the minority colony), between colony ring movements are indicated by colour coded weighted lines.

E) Between roost movements of ringed male bats, colour coded per social group.

F) The percentage of male ring capture records that occur within each social group, in mixed roosts, or as between colony ring movements. 


\section{Figure 4}

Download source file $(162.46 \mathrm{kB})$

a)

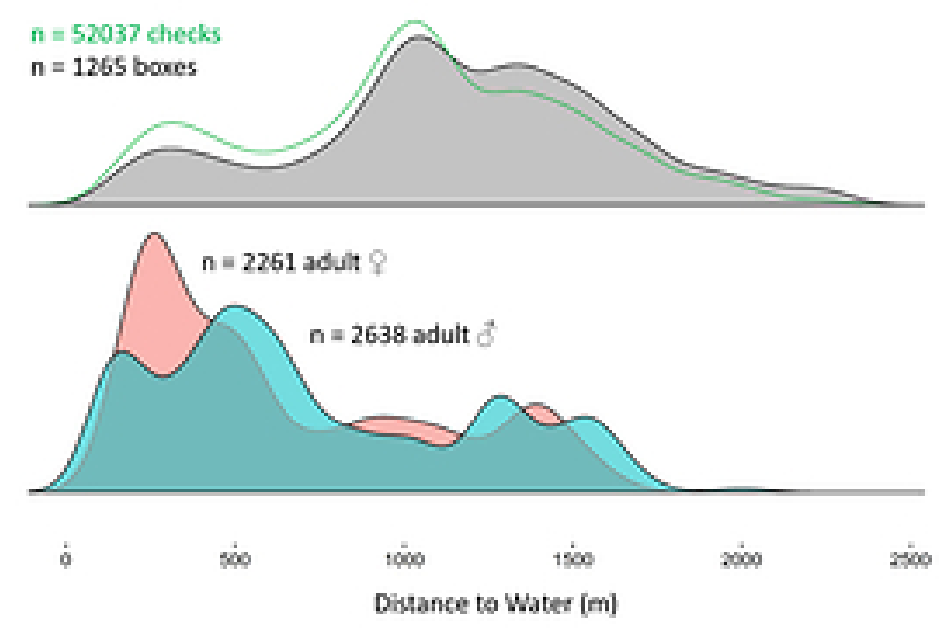

b)

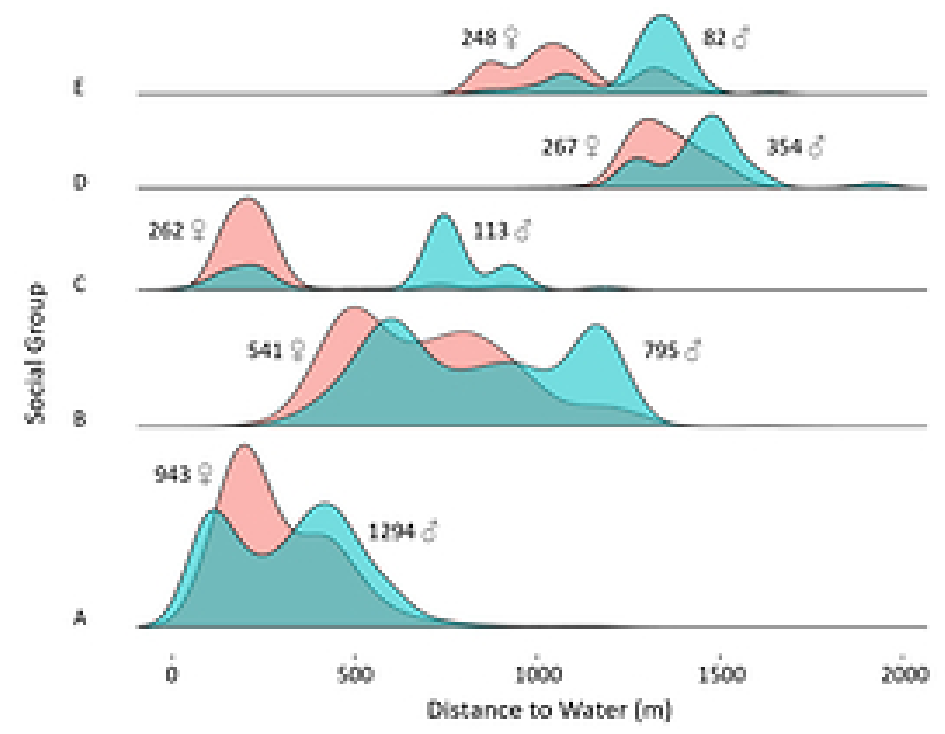

Figure 4. Density plots of the spatial distribution of A) boxes (grey) survey effort (green line), and encounters with ringed adult female (pink) or male (blue) Myotis daubentonii in roosts relative to distance from water, and B) ringed adult bat encounters per social group (A - E). 


\section{Manuscript body}

Manuscript body 1 - Download source file $(51.45 \mathrm{kB})$

\section{Figures}

Figure 1 - Download source file $(745.2 \mathrm{kB})$

Figure 1. Location map of study area, including potential Myotis daubentonii foraging habitat (open water) in the surrounding landscape (lowland floodplain of the River Thames, Oxfordshire, $\mathrm{UK})$.

Figure 2 - Download source file $(805.05 \mathrm{kB})$

Figure 2. Seasonal patterns in Myotis daubentonii roost composition and group size, for A) bachelor (adult male dominated) groups, and B) maternity (adult female and/or juvenile dominated) roosts. Pie charts each represent a day roost and depict the proportion of adult males (dark blue), adult females (dark pink), juvenile males (light blue) and juvenile females (light pink) present. Maternity groups that were not disturbed, so their exact composition is unknown, for which the group size was estimated are also shown (empty pink circles).

Figure 3 - Download source file (2.01 MB)

Figure 3. Spatial distribution of Myotis daubentonii day roosts and ring movements per social group across Wytham Woods.

A) bachelor (adult male dominated) groups (blue) and maternity (adult female and/or juvenile dominated) colony day roosts (pink) are shown with circle size indicating group size ( $\mathrm{n}=1-45$ bats per day roost, and 1 - 12 known occupations per box, $\mathrm{n}=1100$ day roosts distributed across 382 boxes).

B) Myotis daubentonii day roosts colour coded by dominant social group (A - E), with roost sharing indicated by coloured outlines representing the colony of bats in the minority (A, B or C).

C) Between roost movements of ringed female bats, colour coded per social group.

D) The percentage of female ring capture records per social group that occur exclusively with other members of that colony (A - E), or in mixed day roosts ('with $\mathrm{A} / \mathrm{B} / \mathrm{C}$ ' for the dominant social group and 'in $\mathrm{A} / \mathrm{B} / \mathrm{C}$ ' for the minority colony), between colony ring movements are indicated by colour coded weighted lines.

E) Between roost movements of ringed male bats, colour coded per social group.

F) The percentage of male ring capture records that occur within each social group, in mixed roosts, or as between colony ring movements.

Figure 4 - Download source file $(162.46 \mathrm{kB})$

Figure 4. Density plots of the spatial distribution of A) boxes (grey) survey effort (green line), and encounters with ringed adult female (pink) or male (blue) Myotis daubentonii in roosts relative to distance from water, and B) ringed adult bat encounters per social group (A - E). 